Research, part of a Special Feature on Resilience Through Multi-scalar Collaboration

\title{
Considering the Relationships among Social Conflict, Social Imaginaries, Resilience, and Community-based Organization Leadership
}

\author{
Max O. Stephenson, $\mathrm{Jr}^{1}$
}

\begin{abstract}
This article focuses on the question of what role community-based organization leaders play in shaping the possibility for the emergence of new social imaginaries. It argues that deep social conflicts and efforts to secure purposive change are likely to demand strong civil society organization response and that certain forms of imagination are necessary and must be actively employed among community-based leaders if new imaginaries are to be discerned and effectively shared in ways that encourage sustained dialogue and the development of new social understandings. The article explores these briefly and draws illustratively upon two relevant examples from the peacebuilding literature to contend that such imaginationled leadership is necessary to catalyze new social imaginaries that can lead to more resilient social orders.
\end{abstract}

Key Words: post-conflict situations; resilience; social imaginaries

\section{INTRODUCTION}

Bercovitch (1996) has observed that the lion's share of enduring social conflicts revolve around dissensual issues over values. These may undermine group capacities even to imagine "the other" with anything besides distrust and disdain. Long-term experience with efforts to address intractable differences has suggested that such antagonism may rest in terror, isolation, and/or ignorance, and that these understandings and the behaviors they imply must change if a new social condition is to obtain (Lederach 1995, 2005). What is less clear is how best to bring about such change and the ways of knowing or understanding such connotes. Some analysts have offered prescriptive processes for mediation while others have embraced so-called Track One or Track Two diplomatic forms and forums of negotiation to address this challenge. This article focuses instead on the question of what role community-based organizations and their leaders may play in shaping the possibility for the emergence of new social imaginaries (Taylor 2004). It argues social conflicts and significant social change are likely to demand strong civil society organization response and that certain forms of imagination are necessary and must be actively employed among community-based leaders if new imaginaries are to be discerned and effectively shared in ways that permit sustained dialogue and the development of new social understandings.

The article explores these briefly and draws upon two relevant examples from the peace-building literature to contend that such imagination-led leadership is necessary to create and to catalyze new social imaginaries that can overcome social conflict and encourage social change, leading to more resilient social orders. The article concludes by identifying characteristics of leadership required to elicit new imaginaries that may successfully address enduring values dissensus in communities.

\section{SOCIAL IMAGINARIES AND SOCIAL CONFLICT}

The philosopher Charles Taylor has argued that community populations come collectively to imagine their lives in specific and often unconsciously shared ways. He labels these "social imaginaries" and suggests that they are variegated and subtle, but no less powerful for possessing those characteristics:

Our social imaginary at any given time is complex. It incorporates a sense of the normal expectations we have of each other, 
the kind of common understanding that enables us to carry out the collective practices that make up our social life. This incorporates some sense of how we all fit together in carrying out the common practice. Such understanding is both factual and normative; that is, we have a sense of how things usually go, but this is interwoven with an idea of how they ought to go, of what missteps would invalidate the practice. (Taylor 2004:24)

In this view it is quite possible for a community's social imaginary broadly to embrace norms that exclude specific populations from enjoying a full share of their human rights, or to include a conception that one or more groups must exist in conflict for whatever constellation of social, political, economic, or other reasons. As Taylor has observed:

At any given time, we can speak of the 'repertory' of collective actions at the disposal of a given group of society. ... The discriminations we have to make to carry these off, knowing whom to speak to and when and how, carry an implicit map of social space, of what kinds of people we can associate with in what ways and in what circumstances. (Taylor 2004:25-26)

Importantly, imaginaries are not theories and, unlike theories, they are held by large groups of people and in the form of widely shared narratives:

\section{I adopt the term imaginary (i) because my focus is on the way ordinary people 'imagine' their social surroundings, and this is often not expressed in theoretical terms, but is carried in images, stories and legends. (Taylor 2004:23)}

For example, much of the population in the South in the United States in the pre-civil rights movement years ascribed to a social imaginary that could not conceive that Rosa Parks, an African-American woman, should possess the right to sit wherever she wished in a public transit bus. Similarly, many families in Northern Ireland during the long years of the "Troubles" acculturated their children to norms that Roman Catholics could not associate with Protestants, and vice versa, and that people from certain neighborhoods in Belfast, Londonderry, and other communities could not associate with those from nearby locations. Violations of these norms were often met with violence, whether the horror unleashed on the Edmund Pettus Bridge in Selma, Alabama on March 7, 1965 during the Martin Luther King, Jr.-led march for civil rights, or the frequent murders and bombings in Northern Ireland during the Troubles, when Loyalist paramilitaries or members of the Irish Republican Army believed that their social understandings had been abridged.

These examples suggest several critical attributes of social imaginaries. First, these conceptions constitute a critical way in which those holding them make sense of their worlds. They represent alternate ways of knowing. Second, however significant and powerful, the rationale or rationales underpinning them often go unarticulated. Rather, they are espoused and motivate action because they constitute widely shared views of the world and how it ought properly to be ordered among members of specific groups or communities. Third, imaginaries govern the possibility and portent of human relationships. Many in the American South could not conceive that African Americans could or should enjoy equal legal rights and social equality. Fourth, imaginaries may be changed, but only if those espousing them are given reason to bring them to consciousness, reflect afresh on their foundations, and embrace an alternate conception.

That is, new imaginaries do not just happen; they are socially constructed. Changing them requires emotional and cognitive work built on interactive processes of individual and social awareness and reflection. That dynamic set of processes may entail violence and sacrifice of the sort experienced by the Selma marchers, as those responding to voices for change lashed out in favor of existing imaginaries. Social change is hard won because it demands both emotional and intellectual work of populations and at a deep level. It demands a shift in values, and therefore in how individuals and populations make sense of their lives.

\section{COMMUNITY-BASED ORGANIZATIONS, RESILIENCE, AND ADAPTIVE WORK}

In a recent work on disaster and resilience, Paton and Johnston (2006) argued that catastrophic natural or human events might be seized as opportunities for communities to catalyze the adaptive work necessary to secure long-lived change in their 
capacities to respond to future such occurrences. Their argument parallels Taylor's philosophic inquiry, but focuses on social response to the aftermath of disaster-induced change rather than on the dynamic construction of potential for change:

\begin{abstract}
In this book, resilience is a measure of how well people and societies can adapt to a changed reality and capitalize on the new possibilities offered. To accommodate the former the definition of resilience here embodies the notion of adaptive capacity.... Neither a capacity to adapt nor a capacity for post-disaster growth and development will happen by chance. Achieving these outcomes requires a conscious effort on the part of people, communities and societal institutions to develop the resources and processes required to ensure this can happen and that it can be maintained over time. (Paton and Johnston 2006:8)
\end{abstract}

These authors recognize that effectively reacting to disaster and creating conditions for sustainability in its aftermath typically requires broad scale adaptation, learning, and change in a community's values. Values and norms inhere first in individuals and must change there, and those new conceptions must be shared and adopted by others thereafter if they are to constitute a new way of knowing in a community. That is, individual perspectives must change and those new views must be diffused across relevant geographic populations before a change in imaginaries may occur. Community-based

nongovernmental organizations and their leaders are well situated to play significant roles in mobilizing constituencies to promote new values and ways of knowing because they are generally trusted by their supporters and often mediate between them and public and international organizations in their areas of service and employ locally legitimate mechanisms as they do so (Menkhaus 1996).

Governments and international organizations also often give these organizations a role by dint of employing many as direct agents of contracted program implementation or by relying on them as first responders in the event of disaster (Paton and Johnston 2006). These roles allow interested NGOs opportunities to offer new paths for future community action and to articulate challenges to existing ones in ways that governments may not always be situated to press. For example, southern state governments were unwilling to change existing Jim Crow practices without substantial civil society organization pressure and then only with the active engagement of the national government. This change process unfolded over time and was surely not the lone product of civil society organization action, but it is unclear whether or when it might have occurred without sustained advocacy efforts by such groups.

Ronald Heifetz has developed the idea of dynamic and evolutionary adaptive change implicit in such efforts in his conception of leadership:

When we teach, write about and model the exercise of leadership, we inevitably support or challenge people's conceptions of themselves, their roles and most importantly their ideas about how social systems make progress on problems. Leadership is a normative concept because implicit in people's notions of leadership are images of a social contract. (Heifetz 1994:14)

This study examines the usefulness of examining leadership in terms of adaptive work. Adaptive work consists of the learning required to address conflicts in the values people hold, or to diminish the gap between the values people stand for and the reality they face. Adaptive work requires a change in values, beliefs, or behavior. (Heifetz 1994:22)

Both adaptive work and adaptive capacity imply purposeful efforts to secure change in existing social imaginaries to further social change (Heifetz et al. 2009). Both require management of the conflicts that arise from any challenge of dominant ways of knowing in a community. Leaders are expected to envision these possibilities and to create conditions that allow their communities to address them. Paton and Johnston argue that such engagement is necessary both to cope effectively with disasters and, in their aftermath, to create resilient communities. Heifetz contends that adaptive work represents the essence of democratic leadership as those charged with community responsibility seek to catalyze community awareness and capacity to secure social learning to address pressing social challenges. 
All three authors agree that the necessary change can occur only if ways and means are found to permit the broader population to reflect on existing social assumptions, consider those in light of current conditions and competing values, and adopt fresh views based on that reflective process. Adaptive work and adaptive capacity alike require that relevant populations come to consider anew their basic assumptions concerning an important issue or issues and often, shift their stance and values concerning those to address changes in social, political, or economic conditions or to realize more fully their own stated aspirations. Heifetz argues that we look to leaders foremost to help frame such choices and their implicit conflicts, and to manage those disputes when they are manifest. Paton and Johnston contend that disaster-afflicted communities must accomplish just such work if they are to create resiliency.

For his part, Twigg has suggested similarly that nongovernmental organizations and other community leaders must work to create what he dubs an "enabling environment" for the development of disaster resilience (Twigg 2007). Enabling environments exhibit a number of characteristics, including political and policy consensus concerning the importance of disaster risk reduction and strong community support for the steps necessary to secure resilience (Twigg 2007). This last requirement suggests a key role for leaders who must attain such outcomes. Heifetz contends that leaders engaged in adaptive work must obtain a number of conditions, including the following, if they are to succeed in overcoming deep social dissensus or to change existing imaginaries:

- Provide those communities affected an opportunity to test their assumptions against current conditions, e.g., to conduct a "reality test" of their perspectives.

- $\quad$ Secure ways and means by which to bring all parties involved to respect the perspectives of all sides to existing conflicts and seek means for those groups to come at least to understand the views of those with whom they see themselves in disagreement.

- Seek mechanisms by which to increase community cohesion around a macrolevel set of shared aspirations.
- Develop shared norms of responsibility taking and learning among all groups involved in community change processes (Heifetz 1994:26-27).

Leaders successful in prompting adaptive work in their communities create thereby an enabling environment for the development of increased community resilience.

\section{LEADERS, ADAPTIVE WORK, AND FORMS OF IMAGINATION ${ }^{[1]}$}

Whatever their character and responsibilities, we ask leaders to help us make sense of our environments. People want to make sense of the world and leaders are pressed to help them do so. To address those claims, however, leaders must first understand the imaginaries or ways in which others are viewing their lives. This they do by exercising a variety of facets of imagination. Four of these capacities, i.e., aesthetic imagination, cognitive imagination, affective imagination, and moral imagination, are briefly catalogued here. Although each is treated as if separate, these forms of imagination overlap and are interrelated in practice. Each aspect of imagination yields information and addresses a dimension or dimensions that are critical for leaders as they engage in the dialectical process of seeking to catalyze adaptive work. The point of this discussion is not that civil society organizations alone can catalyze social change, but that the leaders of such entities are neatly positioned to press for (re) examination of prevailing views when even government officials cannot and that they exercise a variety for forms of imagination as they do so. Again, they are not alone in employing these capacities, but their efforts may help to elicit changes in attitudes or understanding when these are necessary to secure purposive social change.

\section{Aesthetic imagination}

Leaders are expected to see possibilities and to discern and develop paths of action that otherwise might go unexplored. One primary mechanism both to comprehend existing perspectives and to challenge those claims is via the aesthetic imagination. As Taylor observed concerning social imaginaries, no form is more powerful than narrative, story, theatre or, poetry, or its equivalent, 
to challenge existing claims. As Maxine Greene has suggested about aesthetics, imagination, and learning:

\begin{abstract}
None of our encounters can happen, however, without the release of imagination, the capacity to look through the capacities of the actual, to bring as-ifs into being in experience. ... Imagination may be our primary means of forming an understanding of what goes on under the heading of "reality:" imagination may be responsible for the texture of our experience. (Greene 1995:140)
\end{abstract}

In his final book, the philosopher Herbert Marcuse offered a thoughtful critique of Marxist aesthetics that suggested similarly that those who exercise high order aesthetic imagination necessarily subvert accepted social norms and mores; that is, they often contest accepted imaginaries. As he observed in The Aesthetic Dimension,

Thereby art creates the realm in which the subversion of experience proper to art becomes possible: the world formed by art is recognized as a reality, which is suppressed and distorted in the given reality. This experience culminates in extreme situations (of love and death, guilt and failure, but also joy, happiness and fulfillment) which explode the given reality in the name of a truth normally denied or even unheard. (Marcuse 1978:6)

We look to leaders to provide just such conceptualizations of possibility and these, as Marcuse would contend, typically "subvert" existing conditions and assumptions. Leaders are expected to see possibilities and to discern and develop paths of action that otherwise might go unexplored. They are further required to undertake these actions in ways that are "visionary," that is, that chart new ways of thinking about a concern. Thus, leaders are asked to address received ways of understanding and not merely to accept them.

Leaders also employ the aesthetic imagination in at least two other ways. First, they are asked to capture the complex in simple and readily graspable terms. This is perhaps especially true in democratic and fast-paced industrialized societies. They are enjoined not merely to spin slogans, which may sadly often be substituted, but to capture in a few words or a brief narrative or symbol a complex reality to obtain a connection and shared aspiration with those with whom they are engaged. Societies, communities, and organizations alike demand these accountings and they stipulate likewise that these renderings be concise, resonant, and powerful, that they be in a word, elegant. Second, leaders are often called upon to identify the criteria by which stories or claims are judged. This powerful role is linked closely to whether leaders are to succeed when they attempt to change the dominant frame or imaginary of the organization, community, or other entity with which they are engaged. In such instances, it may not be sufficient to offer a compelling narrative or story alone. It may also be necessary to provide an alternate set of criteria by which competing claims ought rightly to be understood.

\section{Cognitive imagination}

Although cognitive imagination is not identified solely by raw intelligence, it nonetheless appears unassailable that leaders must possess the necessary acumen to sort through complex concerns, understand them, and suggest mechanisms by which they might reasonably be addressed (Northouse 2007). This facet of imagination also requires leaders to help citizens or stakeholders make sense of their environments at various analytical scales, whether these are nations, subnational political jurisdictions, communities, or organizations. Organizations, whether for-profit, nonprofit, or public, may not change course unless alternate conceptions of shared purpose or processes are brought to the fore and present conceptions are challenged. Citizen and stakeholder groups implicitly, and often explicitly, ask leaders to see relationships among ideas, concerns, or connections they might not, to suggest how those claims are related and then to use their aesthetic imagination to provide a narrative of meaning linked to what they seek to describe.

This set of capacities demands high-order analytical thinking at what some scholars have dubbed the metacognitive level (Turiel 1983, Kohlberg and Candee 1984). Metalevel analysis suggests that leaders are not only expected to grasp and wrestle with complexities and to make sense of them, but also to stand above them to be able to describe in compelling ways their underlying structure and relationships to allied concerns. That is, they must make plain to their constituents their understanding 
of how the issues under consideration might be viewed and why in convincing ways. Addressing that imperative requires strong cognitive reasoning.

\section{Affective imagination}

Leaders are expected to exercise high-order interpersonal communication capacities (Graen and Uhl-Bien 1995). These typically require that they be able to function comfortably with diverse individuals and communicate clearly and effectively as they do so (Fisher and Ellis 1990, Senge et al. 2004). In addition, these capacities demand at their core two additional capabilities. First, many leadership scholars suggest that leaders must operate from profound self-knowledge (Burns 1978, Heifetz 1994, Senge et al. 2004, Northouse 2007). Such self-awareness may allow them to control their reactions and to discipline themselves as they relate to others with whom they may have differences, or who present difficult challenges emotionally or intellectually. Second, successful leaders exude and practice actively what has been variously labeled other-regardingness or empathy (Turiel 1983, Hoffman 2000). They appear able to perceive the needs of those with whom they interact and genuinely to appreciate and act on those requirements. Each of these matters merits brief consideration.

Self-knowledge provides leaders a dais on which to stand as they consider possibilities and the views of others with whom they are engaged. Selfknowledge permits leaders to listen actively and to discern the assumptions as well as articulated needs of constituents and stakeholders (Fisher 1997). Personal awareness also permits leaders to negotiate alternate ways of knowing and to craft metalevel cognitive possibilities because it implies selfknowledge of just these concerns. Self-knowledge permits a more open and empathetic response to other ways of knowing because one understands one's own imaginary well. Listening attentively and openly to those ideas and epistemologies offered by others, even when these deeply contravene one's own, is made possible, if not always comfortable, by that personal knowledge and continuing process of reflection (Gilligan 1982).

\section{The moral imagination}

In a thoughtful book concerned with international peacebuilding efforts in which he reflected on decades of seeking to resolve deep impasses and conflicts, John Paul Lederach defined the moral imagination generally as " ... the capacity to imagine something rooted in the challenges of the real world yet giving birth to that which does not yet exist" (Lederach 2005: 29). For his part, and similarly, the influential critic and thinker Russell Kirk popularized the idea of the moral imagination in recent years. Wesley McDonald has sought to capture Kirk's understanding of the moral imagination:

Kirk described the moral imagination "as that power of ethical perception which strides beyond the barriers of private experience and events of the moment, especially the higher form of this power exercised in poetry and art. ... A uniquely human faculty, not shared with the lower forms of life, the moral imagination comprises man's power to perceive ethical truth, abiding law in the perceived chaos of many events." Without the moral imagination, man would live merely from day to day, or rather moment to moment, as dogs do. "It is the strange facultyinexplicable if men are assumed to have an animal nature only-of discerning greatness, justice and order beyond the bars of appetite and self-interest." (McDonald 2004:55)

McDonald's characterization suggests that exercise of the moral imagination demands that its practitioner act on behalf of a collectivity beyond self. The moral imagination is therefore innately creative and intuitive even as it is concerned with needs beyond those that serve the leader alone. Artful use of the moral imagination will cause leaders first to consider alternate social assumptions and second, to seek creatively to deepen mutual awareness of what they discover in so doing. As they do this, they will seek to look outside themselves both to ascertain needs and to justify and legitimate how they act to address them. As such, the moral imagination is at once an attitude, a moral claim, and an acuity.

If community-based NGO leaders employ these facets or forms of imagination, they will do so in a specific historical, social, and economic context. 
The analysis turns next to a discussion of the roles of NGOs as they seek to catalyze adaptive work and address long-lived social conflicts. Following an introduction, the discussion highlights two case examples to suggest the ways in which contexts may shape NGO capacity and scope for action. Thereafter, the paper turns to a discussion of the characteristics of community-based leadership and the role of the various forms of imagination in securing adaptive change.

\section{ENDURING SOCIAL CONFLICT, PEACEBUILDING NGOs, AND ADAPTIVE WORK}

It is unfortunately not difficult to develop a list of nations and communities in which various forms of long-lived social conflict have led to violence and varying degrees of breakdown of civil order. Recent examples include Northern Ireland, Kenya, Ivory Coast, Sri Lanka, Somalia, Israel/Palestine, and the former Yugoslavia. This roll suggests no dearth of opportunity for NGO leaders to engage in the exercise of the forms of imagination treated above and to press efforts to create enabling environments that permit the adaptive work necessary to allow the conflicting parties and their communities to come to acknowledge the imaginaries of "the others" in their conflicts. These disputes are multifaceted and rooted deeply in historical conditions and perceptions (Goodhand and Lewer 1999, Shirlow and Murtagh 2006). Some are tied to ethnicity, others to economic conditions, some to religious beliefs, still others to conflicts over territory, and some exhibit elements of all of these factors and more. Indeed, most perduring social conflict is multivalent. The role of community-based NGOs in two such conflicts, in Northern Ireland and in the former Yugoslavia, is treated briefly below to suggest the ways in which each raised prevailing imaginaries to view and articulated alternatives for public consideration.

What is most pressing in addressing any abiding social conflict is the development of mechanisms that allow the parties both to grasp and respect the imaginaries of the other and to act on that knowledge in good faith thereafter to create new and shared possibilities that may then guide new behaviors and efforts to change community conditions. This may occur in any number of ways and generally must obtain among actors across analytic scales as well (Elliott 2002). NGO/civil society organization leaders may play important roles in allowing for the evolutionary social learning processes aimed at securing a modicum of understanding across social divides. Cochrane (2000) has argued, for example, that peace and conflict resolution, communitybased organizations were cumulatively key to the development of the historic 1998 Good Friday Agreement in Northern Ireland. These organizations' efforts were not always obvious and frequently, indeed, were not visible to the general public, but they were nonetheless vital:

\section{Consequently, it is important to make some assessment of the impact of the P/CRO (peace and conflict resolution organizations) sector on the 'peace process' in Northern Ireland and its contribution to civil society generally. Actually doing this is extremely difficult in practical terms. In reality, much of the most useful activity in this field is conducted invisibly and is not tied to particular events. It is often not appreciable when it is carried out, its value only becoming apparent in combination with other events and actions when viewed over time. ... While undramatic, it is fair to conclude that the greatest long-term impact of the sector was provided at the micro-level by 'unsung heroes' who provided the glue which held society together during the worst periods of conflict. (Cochrane 2000:17-18)}

One such organization in Northern Ireland is the Community Arts Forum. The Forum, the 1993 brainchild of Belfast artists Tom McGill and Martin Lynch, sought self-consciously to devise community-based art that transcended the typical cultural divide that separated even artistic efforts in that divided province. One such initiative, conceived in 1997 by Lynch and playwright Jo Egan and researched and written with broad community involvement in 1998 and 1999, was a crosscommunity play, the "Wedding Play," produced in late 1999 by 11 different Catholic and Protestant arts groups (Cleveland 2008). As its title suggests, the play featured a wedding, in this case between a young couple from Catholic and Protestant working class Belfast neighborhoods respectively, and was staged in multiple neighborhoods while featuring 60 performers from both sectarian communities.

The Wedding Play's creators exercised affective imagination in bringing the disparate groups involved across sectarian lines in a joint production 
whose staging required travel and set-up among several private residences in Protestant and Catholic neighborhoods. The two demonstrated empathetic imagination in building the trust necessary to cross long-standing animosities to produce a theatrical event that dealt with the improbable and difficult challenges of Catholic-Protestant intermarriage as metaphor for a broader social possibility and its related dilemmas. Egan and Lynch practiced cognitive imagination by envisioning the possibility of the collaboration, despite obvious specific roadblocks among neighborhood subpopulations, ongoing community violence, and prevailing social assumptions. These leaders also exercised moral imagination by persevering in a vision of hope and normative change anchored in an alternate social imaginary and symbolically represented by the play.

Finally, in undertaking the play's production and the cross-community resident involvement it entailed, these artist-leaders created an enabling environment for continuing dialogue concerning how deeply divisive and enduring social conflicts might be addressed and what factors, precisely, fostered their continuation.

The feminist Yugoslav peace-organization Women in Black-Serbia (WIB) defined peace not simply as the absence of social conflict, as had their Irish counterparts, but also as the replacement of a regime perceived as illegitimate with one dedicated to social justice rooted in political equality. This need arose as a result of the atrocities committed by and in the name of the Milosevic regime during the Yugoslav war in the 1990s. WIB advocated for regime change from its founding in 1995 until the conflict's end, and thereafter has pressed for governmental accountability for atrocities by a variety of public advocacy-related activities. These have included the collection and publication of oral histories of women who lost their children to the horrors of that Balkan conflict and who often still do not know their loved ones' whereabouts (Zajovic et al. 2007). The group has also led a long series of symbol-laden public demonstrations and street events aimed at raising the salience of the Srebrenica massacre and demanding a formal regime apology for that horrific event (achieved in 2010, although controversy still reigns regarding the adequacy of that formal statement) and partnered with community-based arts organizations, including the theatre company DAH, to highlight the tragedies wrought by the war and to call for transitional justice. Most recently, WIB has teamed with a variety of other NGOs to press for creation of a civil society-based Regional Fact Finding Commission on the Victims of Wars in Former Yugoslavia to secure accountability across the war zone for those who perpetrated war crimes. WIB has also pursued a publications program in English as well as Serbian to highlight its claims (Vuskovic and Trifunovic 2008).

The group's leaders have systematically employed aesthetic imagination to design symbolic events to highlight their claims and to garner public dialogue, including a partnership with the Belgrade based DAH theatre. WIB has similarly employed cognitive imagination both to develop the evidence necessary, often oral histories, to press its claims in the public square and to position those as effectively as feasible in the broader public's consciousness.

Stasha Zajovic and other WIB leaders have built coalitions among an array of NGOs around calls for justice for victims of genocide, military rape, and other war crimes. These have required a capacity to reach a variety of constituencies and elicit their cooperation and support even as it has demanded often intricate interorganizational communication. Both of these have required continuing exercise of affective imagination.

Finally, Women in Black-Serbia has tied its advocacy efforts to a vision of an alternate society in which those wronged by the war attain justice and a new social order is created that removes the various social tensions and fissures that underpinned the conflict. Creating and sustaining this vision has required moral imagination.

In Northern Ireland, the Community Arts Forum worked tirelessly to address the fear, hatred, and historical divisions that separated the contending parties to produce a play designed self-consciously to stimulate public dialogue on those concerns. The aim was to convince those who experienced the production at least to imagine the possibility of living as family with those whose outlook and upbringing did not match their own. Each had to accord negotiating status and legitimacy to the other and at least to countenance the development of a new imaginary. In Serbia, WIB has employed a wide variety of often symbolic advocacy activities both to obtain justice for victims of war crimes and to argue for a changed social imaginary that would ensure those atrocities would not be repeated. As in Northern Ireland, WIB's leaders had not only to 
envision, but also to press for development of processes aimed at securing peaceable opportunities for ongoing dialogue among contending groups to address latent assumptions that constituted the existing social architecture of shared community meaning. That is, each group's leaders has led efforts to challenge existing widely held assumptions about "the other" and to press for dialogue about what the assumptions of a new social imaginary might be.

\section{CHARACTERISTICS OF NGO LEADERSHIP FOR SOCIAL CHANGE}

These brief sketches of the roles played by these two NGOS in two disparate contexts and geographic locations that have addressed long-lived social conflicts illustrate the ways these organizations and their leaders sought to encourage adaptive work in their communities. In each case, and despite very different circumstances, these entities sought to contribute to the construction of more peaceful social conditions and thereby greater social resilience. In each instance, leaders of these organizations employed a variety of processes and means to address the foundational assumptions that underpinned the perspectives that needed consideration if social change was to occur.

Whatever the mechanism employed, leaders had to devise creative strategies and narratives to bridge the divides that split their populations and subverted existing understanding (aesthetic imagination); had to be able to articulate perspectives that "made sense" to their community's residents, but that nonetheless offered new ways of knowing (cognitive imagination); had to share those ideas in ways that could be heard by all, even if that message was challenging (affective imagination); and had finally to make ethical and moral claims that could be understood and be seen as sufficiently compelling (moral imagination) so as to elicit the prospect of respectful dialogue from all concerned.

NGO leaders and their organizations had, in short, to address their community's divides while securing conditions for social learning. Such change demanded new ways of knowing and did not come easily. The mechanisms these organizations employed to address this principal goal were diverse. Whatever the strategy and audience, however, NGOs and their leaders had to understand the values and claims that underpinned the social imaginaries at play in their contexts and find alternate ways of viewing their roles in the commons that the community's population could consider and that held the prospect for offering an alternative to broadly shared existing ways of knowing (Goodhand and Lewer 1999).

\section{CONCLUSIONS}

Instead of focusing on strategies or tools for redressing conflict, this article has explored the nature of the challenge confronting NGOs as they seek to address enduring social divisions in their communities. When long-lived, these social conflicts are typically architectonic in character and ultimately require that these organizations and their leaders work to create conditions in which those on different sides come first to reflect on their own ways of knowing and thereafter to consider respectfully those of their perceived "opponents." Either of these challenges alone is daunting, but when highlighted together, the enormity of the obstacles becomes clear. Would-be peacebuilding leaders must chart contrasting imaginaries, must craft approaches to bring individuals and competing leaders alike to reflect on them, and must manage the conflict these steps are almost certain to create. But they must do more. Even as they uncover assumptions for fresh scrutiny in the name of new possibilities, they must also convince those involved that the risks implicit in changed assumptions and behaviors are worth bearing and can be justified on grounds that make moral and cognitive sense. This set of responsibilities is addressed necessarily in a dynamic historic and social context in which missteps can create large setbacks and the possibility of ruinous conflict. There is no substitute for thoughtful and sustained engagement that builds trust and allows for the possible development and articulation of different social imaginaries.

Accordingly, this article has argued that community NGO leaders seeking to secure peace employ a variety of facets or forms of imagination as they seek to meet these challenges. They must employ aesthetic imagination literally to conceive of ways of knowing that possess the power to subvert existing claims. They must utilize affective imagination in countless meetings and public events to broker trust and legitimacy and to come to understand more fully the hopes, fears, and assumptions of all sides to their community's 
central conflict. They must also use their cognitive imagination to analyze possibilities for future action and to craft strategies aimed at eliciting their discussion and refinement. Finally, and overarchingly, their efforts must be driven by a moral attachment to the common good of their community and to the hope represented by the effective amelioration of the conflict dividing it. They must be driven by a passionate regard for the future and for the ethical mitigation of conflict in their midst.

Paton and Johnston (2006) suggested that postdisaster efforts to build community resilience requires the rethinking of the ways of life and of living that antedated specific disaster events. This may require living in alternate locations, changing the mix of economic activities that sustain community life, or overcoming long-standing dissensus among different social groups, or all of these. Community resilience in short demands more than effective disaster planning, as important as such efforts may be. It demands social learning and artful leadership aimed at creating enabling environments for just possibilities to occur.

Given the complexity and interdependent array of actors involved in creating, sustaining, and changing community social imaginaries, these are unlikely to shift magically with adoption of one or another strategy, tool, or technique by either political or civil society actors. However, sustained efforts to clarify and articulate differences and similarities among the parties as well as to identify their hidden and often unarticulated assumptions concerning existing ways of knowing and community organization may allow civil society leaders to play important roles in these critical processes. To the extent they do so successfully, they can contribute significantly to the development of public consideration of social imaginaries and their self-conscious (re)creation over time around new assumptions and claims. There can be no gainsaying how difficult such efforts are, but their attainment, as reflected through alternate imaginaries, is critical to the long-term resilience of disaster afflicted and conflict-ridden communities alike. This goal, as the old axiom had it, is well worth the candle expended to pursue it.

[1] This section is adapted from Stephenson Jr., M. O. 2009. Exploring the connections among adaptive leadership, facets of imagination and social imaginaries. Public Policy and Administration 24 (3):417-435.
Responses to this article can be read online at: http://www.ecologyandsociety.org/volXX/issYY/artZZ/ responses/

\section{Acknowledgments:}

The author acknowledges with sincere thanks Leah Wickham's research assistance in the development of this article.

\section{LITERATURE CITED}

Bercovitch, J., editor. 1996. Resolving international conflicts: the theory and practice of mediation. Lynne Reinner, Boulder, Colorado, USA.

Burns, J. M. 1978. Leadership. Harper and Row, New York, New York, USA.

Cleveland, W. 2008. Art and upheaval: artists on the world's frontlines. New Village Press, Oakland, California, USA.

Cochrane, F. 2000. Beyond the political elites: a comparative analysis of the roles and impacts of community-based NGOs in conflict resolution activity. Civil Wars 3(2):1-22.

Elliott, M., editor. 2002. The long road to peace in Northern Ireland. Liverpool University Press, Liverpool, UK.

Fisher, D. 1997. Communication in organizations. West Publishing, St. Paul, Minnesota, USA.

Fisher, B. A., and D. G. Ellis. 1990. Small group decision making: communication and the group process. Third edition. McGraw Hill, New York, New York, USA.

Gilligan, C. 1982. In a different voice: psychological theory and women's development. Harvard University Press, Cambridge, Massachusetts, USA.

Goodhand, J., and N. Lewer. 1999. Sri Lanka: NGOs and peace-building in complex emergencies. Third World Quarterly 20(1):69-87.

Graen, G., and M. Uhl-Bien. 1995. Relationshipbased approach to leadership: development of 
Leader-Member Exchange (LMX) theory of leadership over 25 years: applying a multi-level, multi-domain perspective. Leadership Quarterly 6 (2):219-247.

Greene, M. 1995. Releasing the imagination: essays on education, the arts, and social change. JosseyBass, San Francisco, California, USA.

Heifetz, R. A. 1994. Leadership without easy answers. Belknap Press, Cambridge, Massachusetts, USA.

Heifetz, R. A., M. Linsky, and A. Grashow. 2009. The practice of adaptive leadership: tools and tactics for changing your organization and the world. Harvard Business Press, Cambridge, Massachusetts, USA.

Hoffman, M. L. 2000. Empathy and moral development: implications for caring and justice. Cambridge University Press, Cambridge, UK.

Kohlberg, L., and D. Candee. 1984. The relationship of moral judgment to moral action. In W. M. Kurtines and J. Gewirtz, editors. Morality, moral behavior, and moral development. John Wiley and Sons, New York, New York, USA.

Lederach, J. P. 1995. Preparing for peace: conflict transformation across cultures. Syracuse University Press, Syracuse, New York, USA.

Lederach, J. P. 2005. The moral imagination: the art and soul of building peace. Oxford University Press, New York, New York, USA.

Marcuse, H. 1978. The aesthetic dimension. Beacon Press, Boston, Massachusetts, USA.

McDonald, W. W. 2004. Russell Kirk and the age of ideology. University of Missouri Press, Columbia, Missouri, USA.

Menkhaus, K. 1996. International peacekeeping and the dynamics of local and national reconciliation in Somalia. International Peacekeeping 3(1):42-67.

Northouse, P. 2007. Leadership theory and practice. Fourth edition. Sage, Thousand Oaks, California, USA.
Paton, D., and D. Johnston. 2006. Disaster resilience: an integrated approach. Charles C. Thomas, Springfield, Illinois, USA.

Senge, P., C. O. Scharmer, J. Jaworski, and B. S. Flowers. 2004. Presence: an exploration of profound change in people, organizations and society. Doubleday, New York, New York, USA.

Shirlow P., and B. Murtagh. 2006. Belfast: segregation, violence and the city. Pluto Press, London, UK.

Taylor, C. 2004. Modern social imaginaries. Duke University Press, Durham, North Carolina, USA.

Turiel, E. 1983. The development of social knowledge: morality and convention. Cambridge University Press, Cambridge, UK.

Twigg, J. 2007. Characteristics of a disasterresilient community: a guidance note. Department for International Development Disaster Risk Reduction Interagency Coordination Group, London, UK.

Vuskovic, L., and Z. Trifunovic, editors. 2008. Women's side of war. Women in Black-Belgrade, Belgrade, Serbia.

Zajovic, S., M. Perkovic, and M. Urosevic, editors. 2007. Womenfor peace. Women in Black-Belgrade, Belgrade, Serbia. 